\title{
CFD Analysis of Golf Ball with Various Turbulence Models.
}

\author{
M.Sundararaj ${ }^{1}$, S.Elangovan' ${ }^{2}$ E.Mahavishnu ${ }^{3}$ \\ 1,2 Professor, Department of Aeronautical Engineering, Bharath Institute of Higher Education and Research, \\ Chennai. \\ ${ }^{3}$ Assistant Professor, Department of Aeronautical Engineering, Bharath Institute of Higher Education and Research, \\ Chennai.
}

Article History: Received: 11 January 2021; Accepted: 27 February 2021; Published online: 5 April 2021

\begin{abstract}
In this research work we investigate the performance of golf ball with 256 circular arc dimples on golf ball. The turbulence characteristics and flow pattern over golf with various velocities investigated by computational fluid dynamics in suitable turbulence model, in addition that the distance covered by a ball and rotational motion characteristics also investigated with same turbulence model.
\end{abstract}

Keywords: Circular arc dimples, Golf ball, CFD

\section{Introduction}

In olden days we design our model without considering the aerodynamics characteristic but later they understood how the aerodynamic force affect the performance that model because the aerodynamics is a dynamic force its creates the aero elastic, buffeting, fluttering, clopping on models like bridges, building, automobiles, wind turbine and sports goods. So while design the these model we should consider about aerodynamics force on model, how much amount of lift and drag force is produced on that model, what is magnitude of circulation based on wind force and dimensions, then only we can define the structural capability, performance of that particular model. The application of aerodynamics not only in aircraft and also is used to design tall buildings, bridges, wind turbine and sports goods.

In this research work we took one sports goods model for our analyzing, the golf ball is taken in account here the golf ball surface shape is modified by while implementing 256 circular arc dimples. The golf ball designed in Solidworks and analyzed in CFD software. The performance of golf ball is measured by while taking the results for wall shear stress, eddy viscosity, pressure and turbulence kinetic energy from these result we can easily understood what is the distance covered by ball and spin rate.

\section{MODELING}

Modeling of golf ball done in solidworks software with the dimensions of $50 \mathrm{~mm}$ diameter with the 256 surface dimples on the golf ball surface CFD domain of golf ball is modeled as 2times of diameter infront of the ball top and bottom also as well as same, in back side 10 times of the diameter is taken for CFD domain modeling

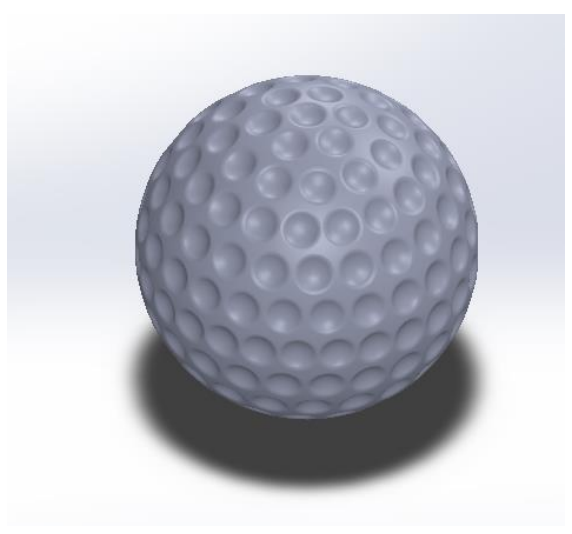

Fig 1: 3D Model of Golf Ball 


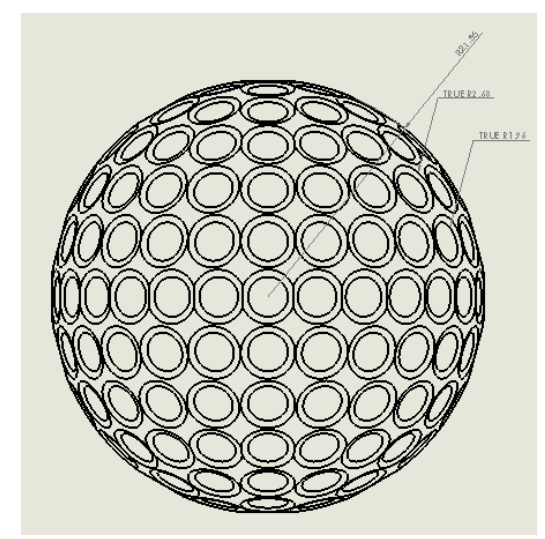

Fig 2: 2D Model of Golf Ball

\section{CFD Simulations}

The CFD simulations of the golf ball is done in ANSYS Fluent Software and the mesh model of the golf ball CFD Domain model is meshed by using Tetrahedral elements with 107546 nodes and 586481 elements

Finite Volume method (FVM) based Solver ANSYS Fluent Software is used for this CFD Simulation with the various turbulence models of k-epsilon, k-omega and SST K-omega model is used for this simulations

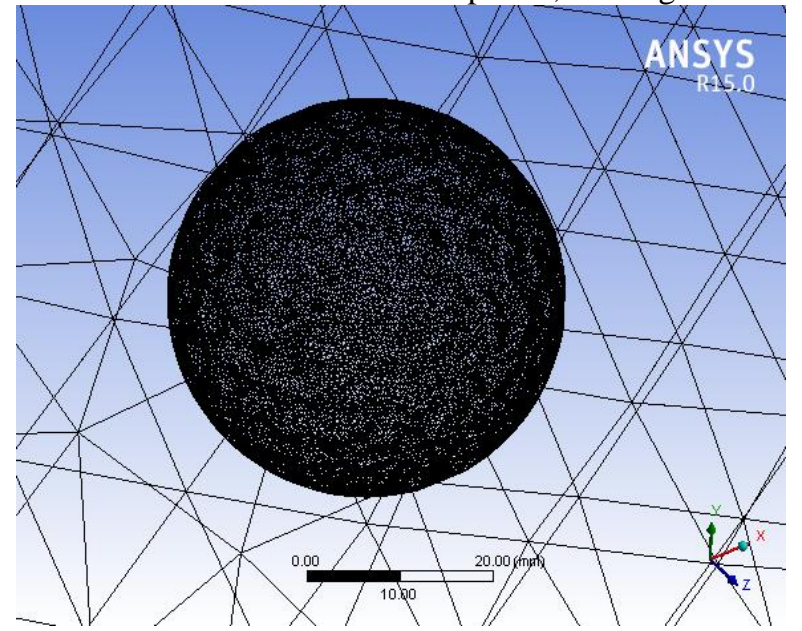

Fig 3: Mesh Model of Golf Ball

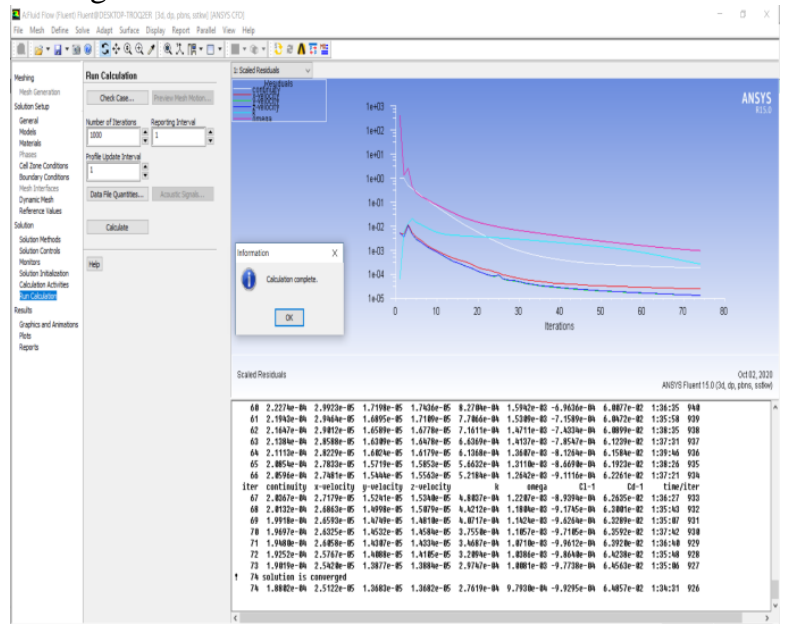

Fig 4: CFD Convergence of Golf Ball analysis

\section{Results and discussion:}

Wall shear stress:
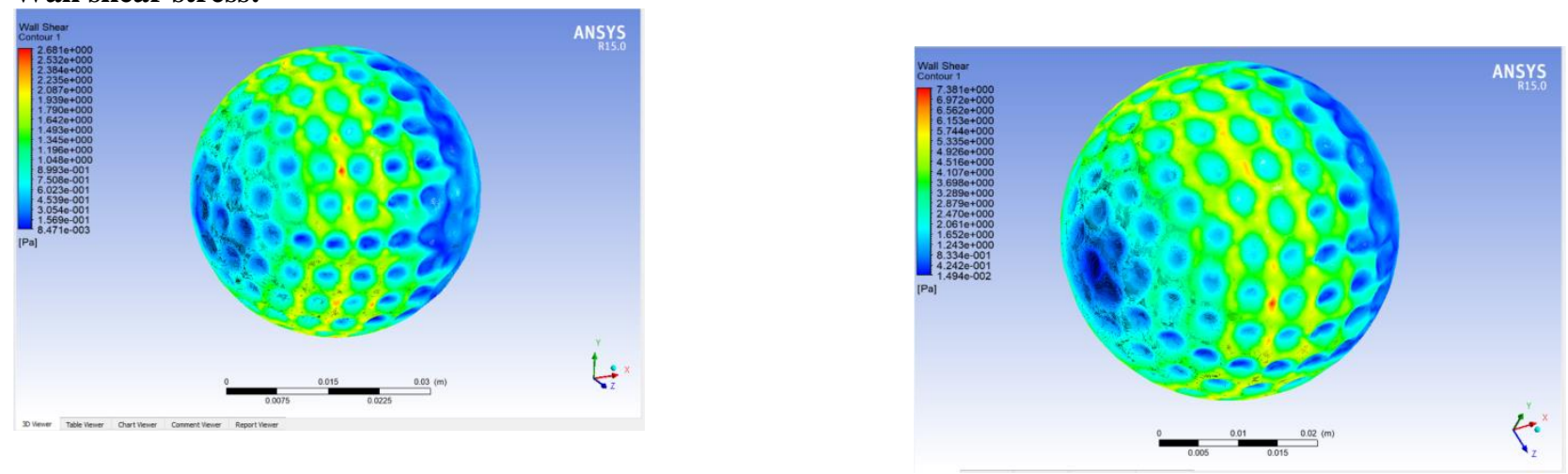

$10 \mathrm{~m} / \mathrm{s}$

$20 \mathrm{~m} / \mathrm{s}$ 


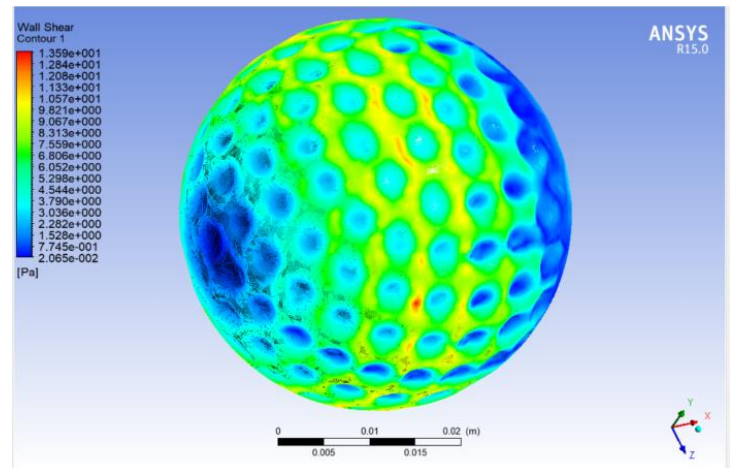

$30 \mathrm{~m} / \mathrm{s}$

\begin{tabular}{|c|c|c|c|}
\hline Wall Shear Stress & K-Epsilon & K-Omega & SST K-Omega \\
\hline $10 \mathrm{~m} / \mathrm{s}$ & 2.482 & 2.586 & 2.681 \\
\hline $20 \mathrm{~m} / \mathrm{s}$ & 7.06 & 7.226 & 7.381 \\
\hline $30 \mathrm{~m} / \mathrm{s}$ & 12.66 & 13.04 & 13.59 \\
\hline
\end{tabular}

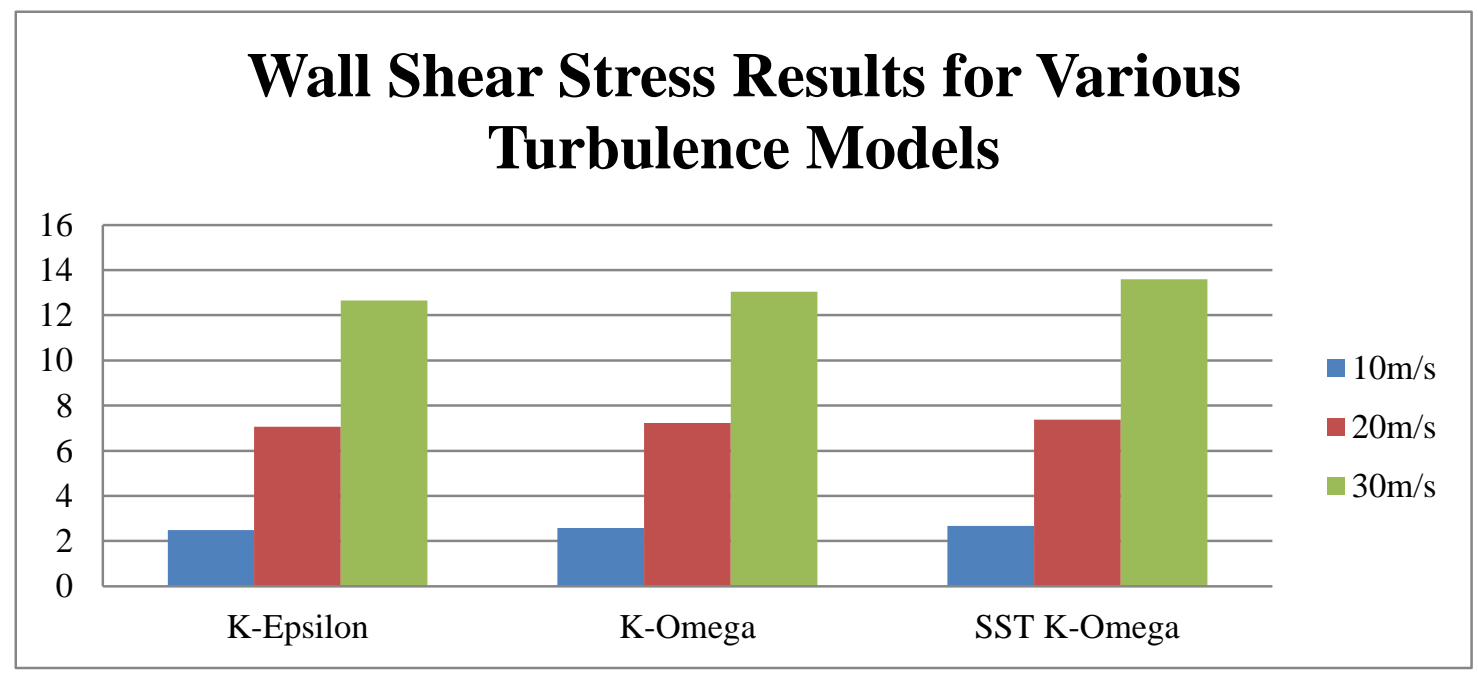

\section{Eddy viscosity}

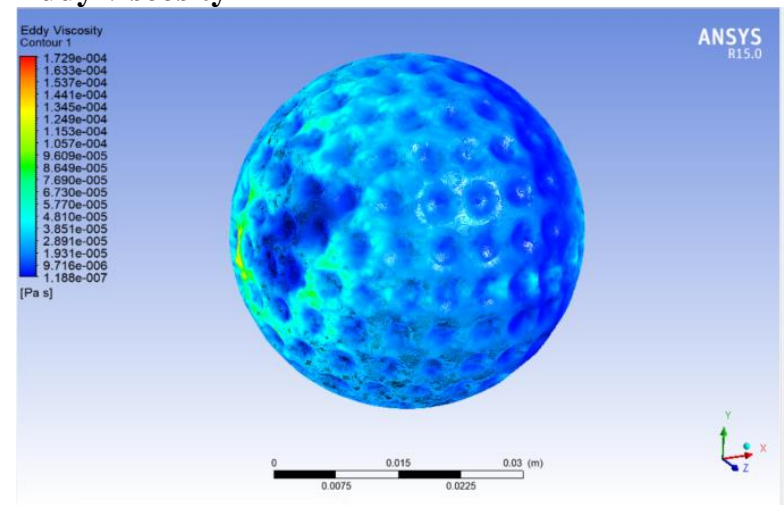

$10 \mathrm{~m} / \mathrm{s}$

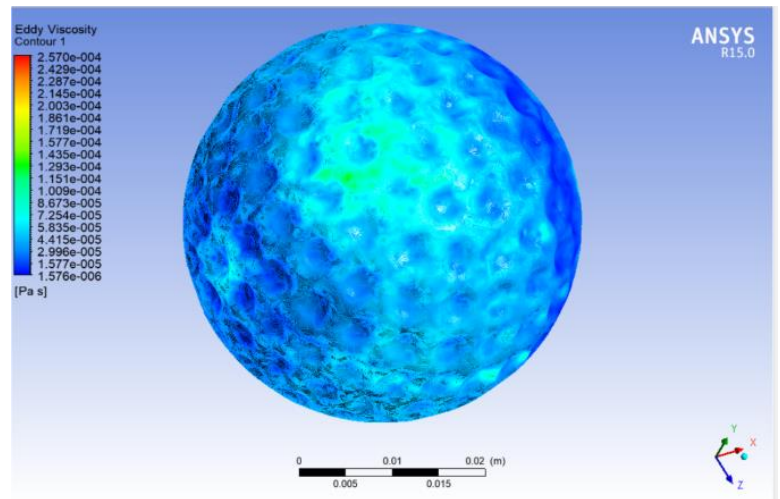

$20 \mathrm{~m} / \mathrm{s}$ 


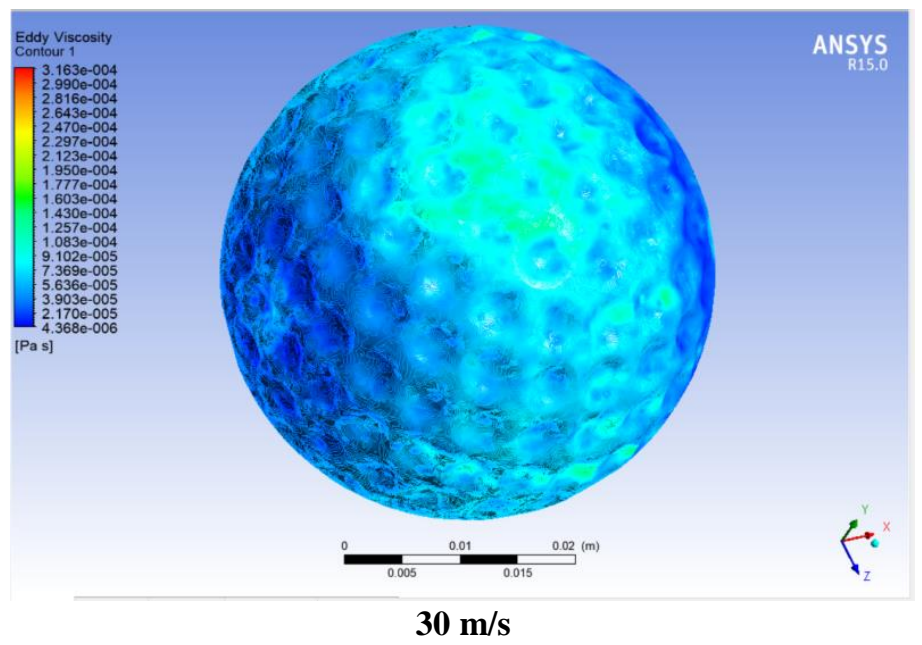

\begin{tabular}{|c|c|c|c|}
\hline Eddy Viscosity & K-Epsilon & K-Omega & SST K-Omega \\
\hline $10 \mathrm{~m} / \mathrm{s}$ & 0.1488 & 0.1655 & 0.1729 \\
\hline $20 \mathrm{~m} / \mathrm{s}$ & 0.2402 & 0.2486 & 0.257 \\
\hline $30 \mathrm{~m} / \mathrm{s}$ & 0.2786 & 0.299 & 0.3163 \\
\hline
\end{tabular}

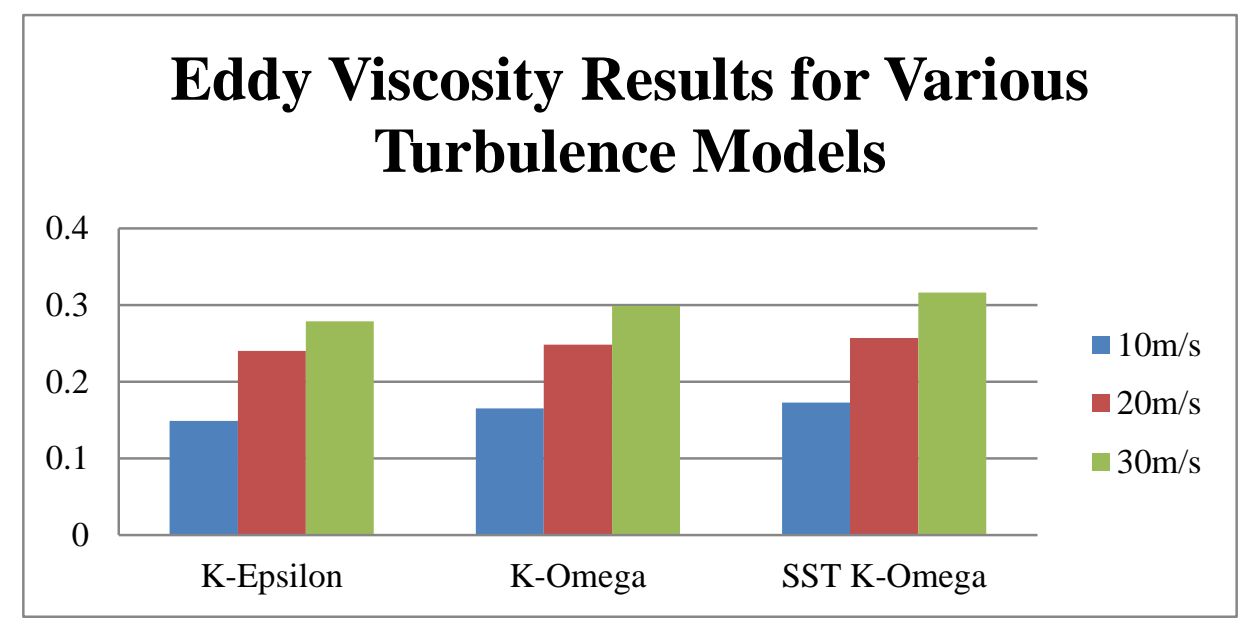

Pressure:
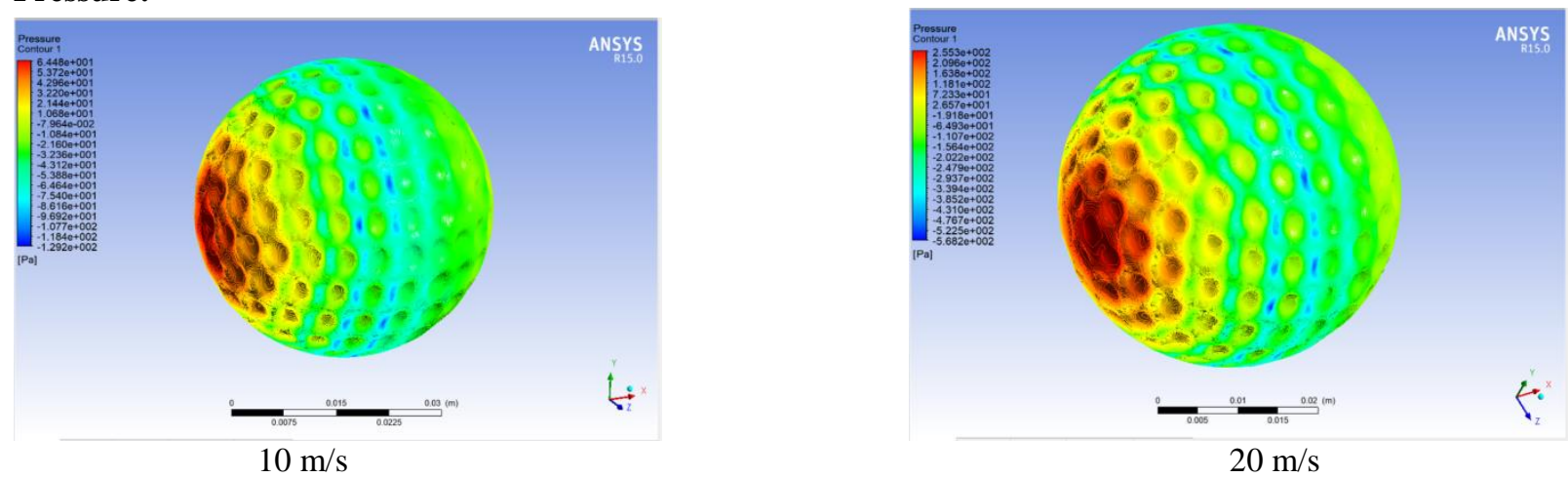


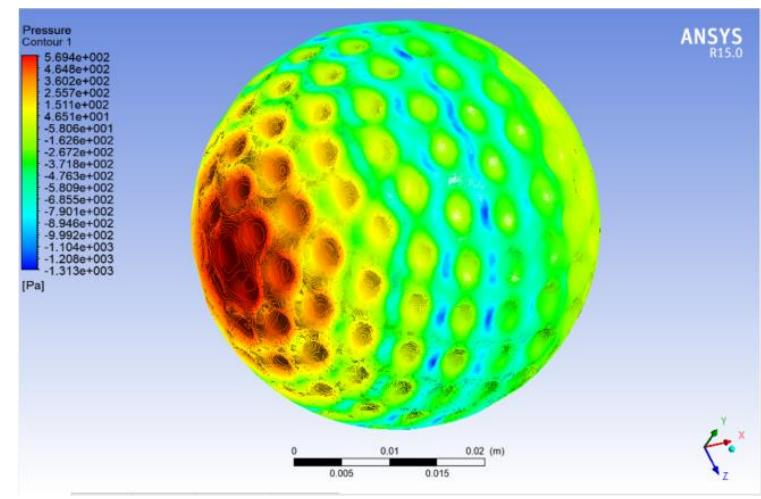

$30 \mathrm{~m} / \mathrm{s}$

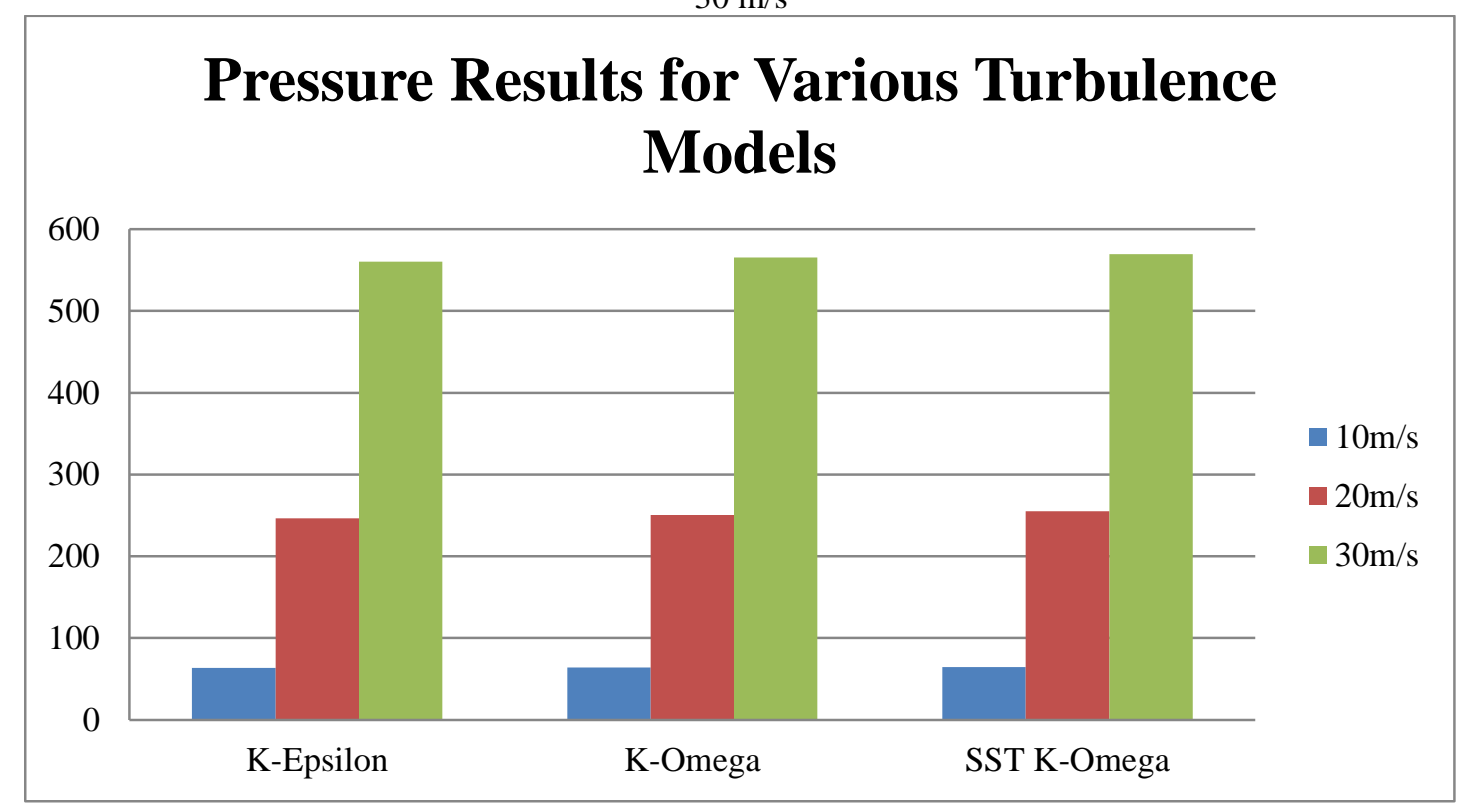

\begin{tabular}{|c|c|c|c|}
\hline Pressure & K-Epsilon & K-Omega & SST K-Omega \\
\hline $10 \mathrm{~m} / \mathrm{s}$ & 63.6922 & 64.225 & 64.48 \\
\hline $20 \mathrm{~m} / \mathrm{s}$ & 246.36 & 250.69 & 255.3 \\
\hline $30 \mathrm{~m} / \mathrm{s}$ & 560.214 & 565.208 & 569.4 \\
\hline
\end{tabular}

Turbulence Kinetic Energy:
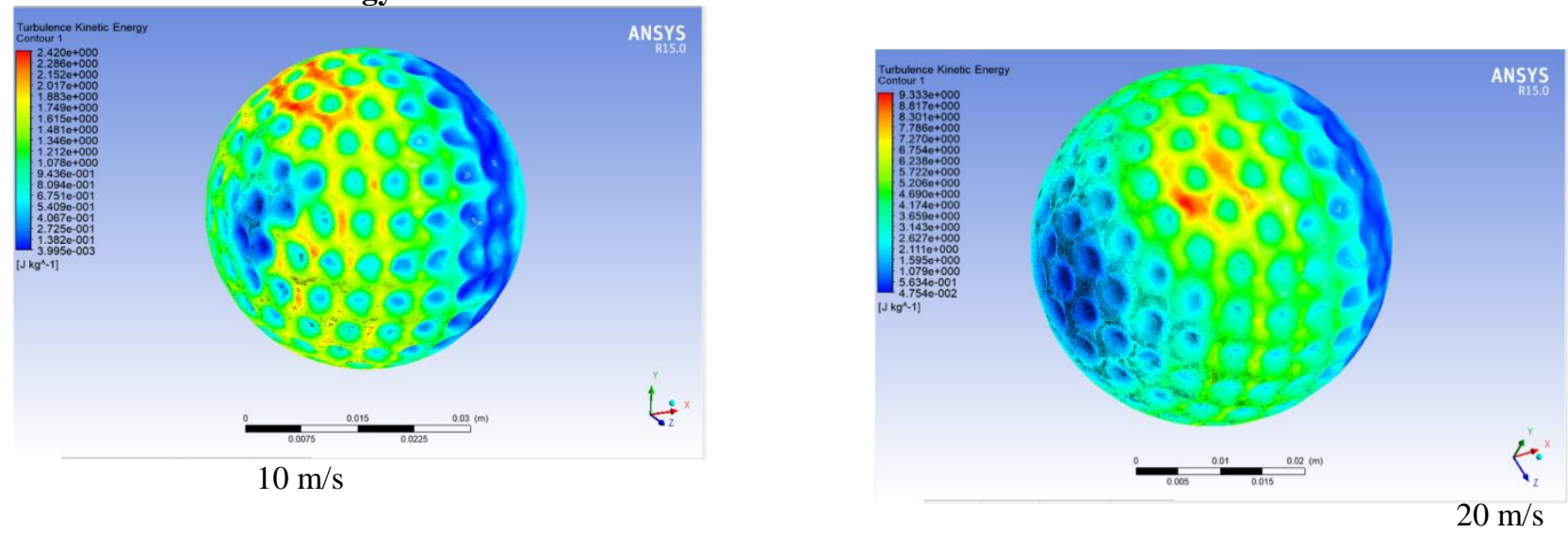


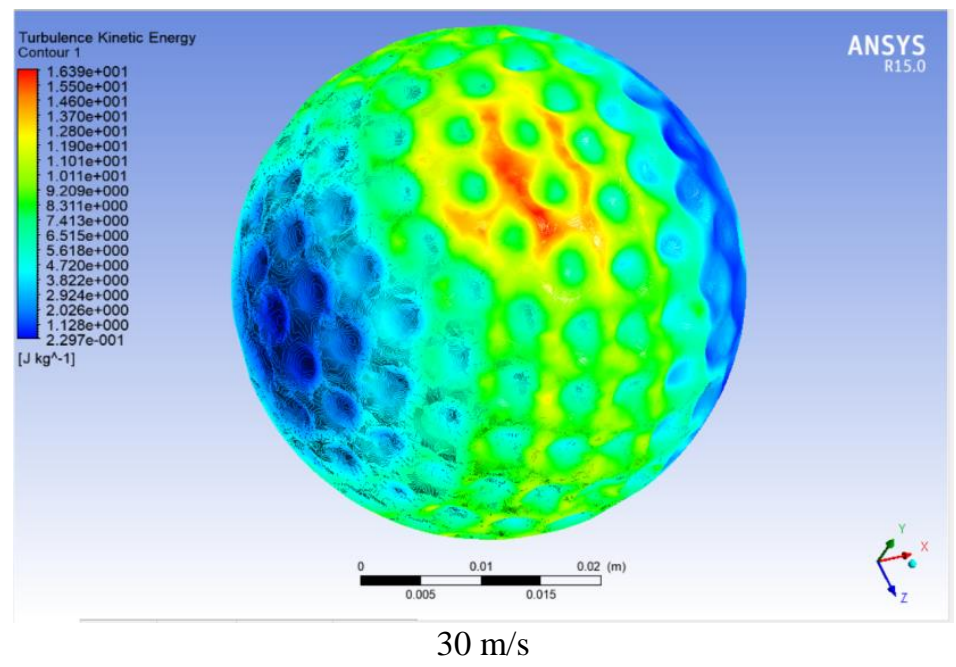

\begin{tabular}{|c|c|c|c|}
\hline Turbulence Kinetic Energy & K-Epsilon & K-Omega & SST K-Omega \\
\hline $10 \mathrm{~m} / \mathrm{s}$ & 1.866 & 2.226 & 2.42 \\
\hline $20 \mathrm{~m} / \mathrm{s}$ & 8.564 & 8.856 & 9.333 \\
\hline $30 \mathrm{~m} / \mathrm{s}$ & 15.24 & 16.02 & 16.39 \\
\hline
\end{tabular}

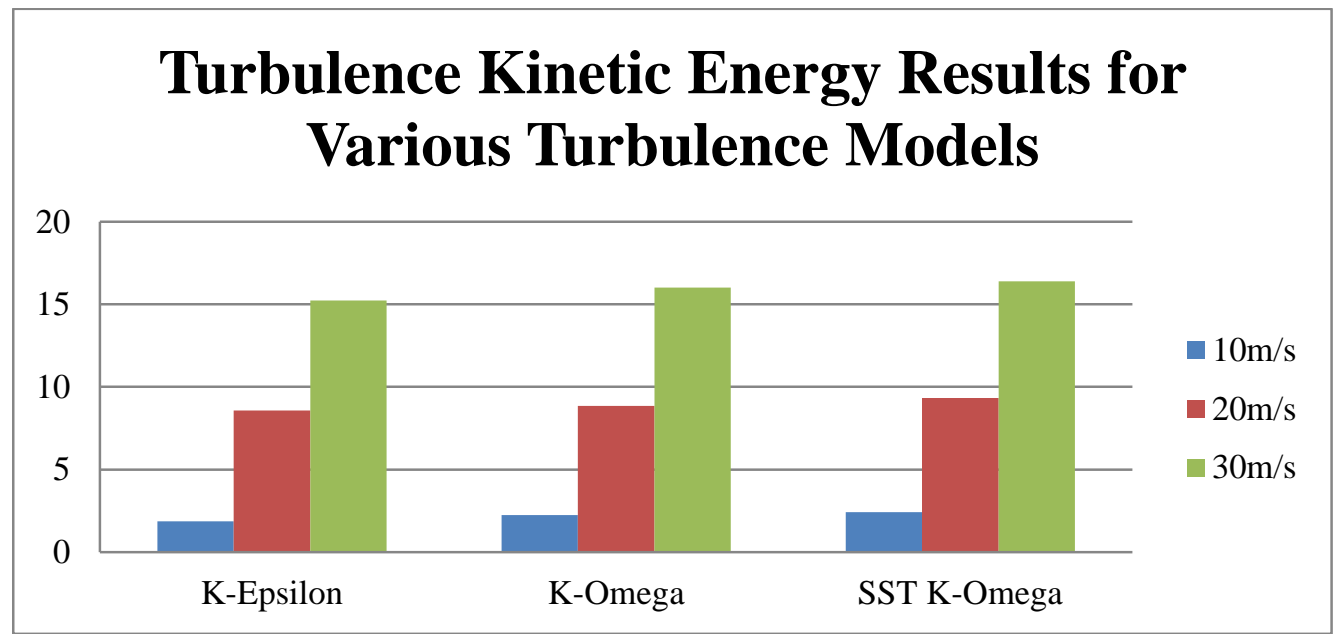

Streamline flow:

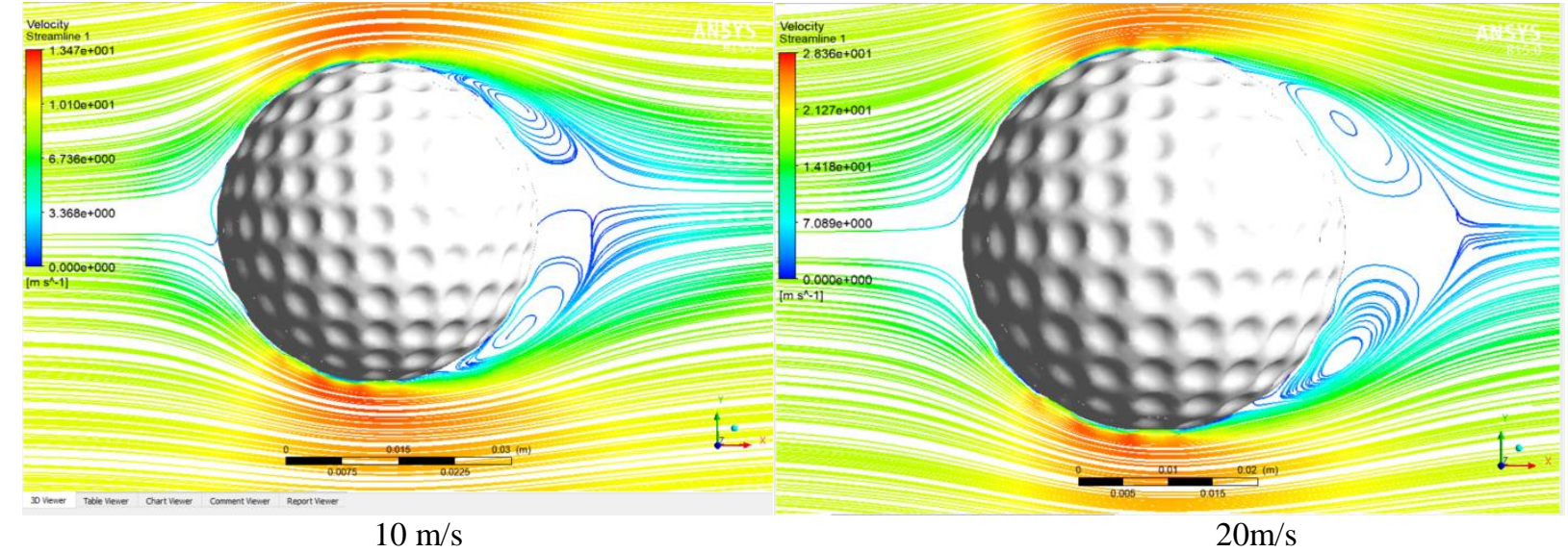




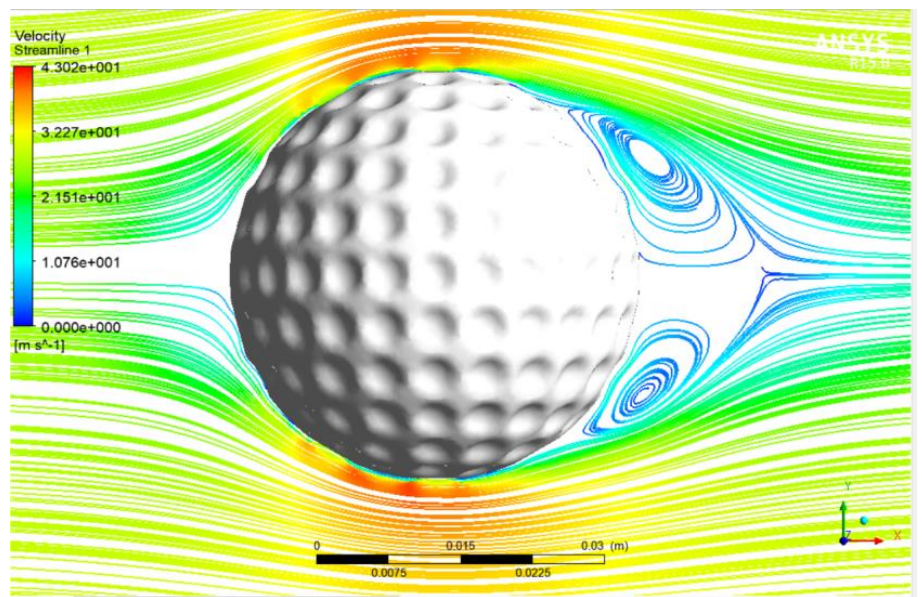

The streamline flow results of golf ball for various flow velocity conditions of $10 \mathrm{~m} / \mathrm{s}, 20 \mathrm{~m} / \mathrm{s}$ and $30 \mathrm{~m} / \mathrm{s}$, in $10 \mathrm{~m} / \mathrm{s}$ velocity conditions wake regions create the circular motions with short distance of vortices, $20 \mathrm{~m} / \mathrm{s}$ flow velocity large distance of vortices and top of the flow low strength and bottom of the ball have more strength of vortices, $30 \mathrm{~m} / \mathrm{s}$ of flow will create the perfect elliptical shape of vortices

\section{Conclusion:}

The Golf ball flow analysis was done in ANSYS Fluent software with the various velocities of $10 \mathrm{~m} / \mathrm{s}, 20 \mathrm{~m} / \mathrm{s}$ and $30 \mathrm{~m} / \mathrm{s}$ of velocities wall shear stress, Eddy viscosity, Turbulence kinetic energy, Pressure results and streamlined flow results can be analyzed with the various turbulence models results comparison will show SST K-omega turbulence models give the better results in the Golf Ball analysis but in the high velocity conditions the wake regions creates the parabolic shapes of vorticies

\section{REFERENCES}

1. Bearman P.W. and Harvey J.K. (1976) Golf ball aerodynamics. Aeronautical Quarterly, 27, 112-122.

2. Smits A.J. and Smith D.R. (1994) A new aerodynamics model of a golf ball in flight. Science and Golf, 2 , 340-347.

3. Ting L.L. (2004) Effects of dimple size and depth on golf ball aerodynamic performance. 4th ASME-JSME Joint Fluids Engineering Conference, 1-7.

4. Aoki K., Ohike A., Yamaguchi K. and Nakayama Y. (2003) Flying characteristics and flow pattern of a sphere with dimples. Journal of visualization, Vol.6, No.1, 67-76.

5. Aoki K., Nonaka M. and Goto T. (2004) Aerodynamic and flying characteristics for the surface structure on the golf ball. Proceedings of the school of Engineering Tokai University, Vol.44, No.2, 67-72.

6. Taneda S. (1957) Negative magnus effect. Reports of Research Institute for Applied Mechanics, Vol.V, No.20, 123-128.

7. Mizota, T., Naruo, T., Shimozono, H., Zdravkovich, M., Sato, F., 2002. 3-Dimensional Trajectory Analysis of Golf Balls, Science and Golf $x$, E \&F.N.Spon, London, pp. 349-358.

8. Naruo, T., Mizota, T., 2004. Trajetory Analysis and Optimum Trajectory of a Golfball, Engineerig of Sport 5, Blackwell Science Ltd., Oxford, pp. 432-439.

9. Sajima, T., Yamaguchi, T., Yabu, M., Tsunoda, M., 2006. The Aerodynamic Influence of Dimple Design on Flying Golf Ball, The Engineerig of Sport 6, Springer Science+Business Media, LLC, pp. 143-148.

10. Kim, H., Onuki, M., Kishibe, S., Tatani,R., Sakaue, S., Arai,T., 2013. Visualization and Measurement of Separation Positions aruound Rotating Dimpled Ball, The Engineering of Sport 9, SciVerseScienceDirect, Elsevier Ltd., pp. 194-199. 